\title{
Current Nutritional Statuses and Gastrointestinal Complications in Critically Ill Patients Admitted to ICUs in Iran: A Cross-Sectional Study
}

\author{
Sahar Rafiee ${ }^{1}$, Zahra Safari ${ }^{1}$, Nafiseh Shokri-Mashhadi ${ }^{1,2^{*}}$ \\ 1-Food Security Research Center, Isfahan University of Medical Sciences, Isfahan, Iran \\ 2- Department of Clinical Nutrition, School of Nutrition and Food Science, Isfahan University of Medical Sciences, Isfahan, Iran
}

\section{A B S T R A C T}

Background and Objectives: Adequate nutrition is closely linked to clinical outcomes. Therefore, this study was carried out to assess nutritional statuses of the ICU patients in Isfahan, Iran.

Materials and Methods: In this cross-sectional study, 55 critically ill adult patients receiving enteral nutrition for a minimum of seven days were participated. Nutritional screening, including acute physiology and chronic health evaluation (APACHE) score, nutrition risk in critically (NUTRIC) score and nutritional assessments of laboratory data, energy and protein balance, was carried out. Moreover, gastrointestinal problems was assessed.

Results: In total, 55 patients (35 men and 20 women) with the median [IQR] age of 49 [18-77] years and the median [IQR] weight of $75(55-100) \mathrm{kg}$ were included in this study. The average of albumin concentrations were $3 \mathrm{~g} / \mathrm{dl} \pm 0.7 \mathrm{in}$ ICU inpatients, indicating decreased albumin levels compared to normal ranges (3.5-5 g/dl). During inpatient period, nutrition screening showed a median range of NUTRIC score of 3 (2-5) and APACHE score of 23 (18-27). In addition, median range of weight decreased to 71 (50-96) $\mathrm{kg}$. Median intakes of energy and proteins for seven days seemed inadequate (1920 [1200-2740] and 86 [49-129], respectively). After gastrointestinal assessment, 20\% of the participants had nausea and vomiting, 10\% had obstipation, 5\% had diarrhea and 20\% had enteral feeding intolerance (assessed by $\mathrm{GRV}>250 \mathrm{~mL}$ at repeated regular $(6 \mathrm{~h})$ measurements).

Conclusions: Results have suggested that although imbalanced energy, insufficient protein intakes, and gastrointestinal complications are common in ICU patients especially in women, risk assessment of malnutrition has shown no critical results. Therefore, designing and providing more sensitive methods for the screening of nutrition and assessment of nutritional adequacy is essential to prevent malnutrition in societies.

Keywords: Intensive care unit, Malnutrition, Nutrition assessment, Gastrointestinal complication

\section{Introduction}

Malnutrition is a spread problem in hospitalized patients; however, this public health problem remains widely unrecognized (1). Poor nutritional statuses can occur due to deficiencies in diet plans, increased nutritional requirements due to illness, complications of diseases, and poor nutrient absorption, or a combination of them $(2,3)$. Based on previous studies, prevalence rates of the hospital malnutrition have been reported at $20-50 \%$, depending on the patient population, and criteria of diagnoses (2-4). In Iran, rates of the hospital malnutrition are reported as nearly $43 \%$ (5). It is well known that insufficient nutritional consumptions can include significant effects in increased risks of infectious and non-infectious complications, prolonged durations of stay at hospitals and intensive care units (ICUs) and further frequent readmissions and mortalities (6-14). In critically ill patients, this condition can be induced by systemic inflammatory responses to critical illnesses or traumas, which increases significant metabolic demands and results in development of malnutrition and further increases in risks of infectious complications, multiple organ dysfunctions and mortalities $(15,16)$.

Numerous studies have revealed that nutritional statuses and cares include significant effects on hospitalization outcomes (17-19). Therefore, nutritional assessment and screening are integral parts of the treatment in critically ill patients (20-22). Biochemical markers, anthropometric indices and food consumption patterns are common 
nutritional assessment criteria of the ICU patients (20). Studies have shown that low circulating levels of magnesium, phosphorus and albumin can lead to energy deficiency and cardiac and neuromuscular disorders (23). Decreased serum potassium levels can results in severe muscle ache and cardiac arrhythmia and arrest (24). Previous observational study has indicated that malnutrition is spread in ICU patients. The study assessed nutritional statuses of 100 critically ill patients admitted to ICUs in a hospital of Al-Zahra University from February to April, 2012. However, daily calorie and protein balances and occurrence of gastrointestinal problems were not assessed in that study (25). Furthermore, biomarkers and indices such as albumin, blood urea nitrogen (BUN), creatinine, potassium and magnesium levels were assessed (25). Due to the high prevalence of hospital malnutrition in Iran, the current study was carried out to assess nutritional status in ICU patients receiving nutritional supports in Isfahan, Iran.

\section{Materials and Methods}

\section{Study design}

This cross-sectional study was carried out to assess clinical nutrition cares in 55 critically ill adults in ICUs in Isfahan from March to May, 2019.

\section{Inclusion criteria}

Patients over 18 years old, hospitalized more than three days in ICUs, received EN and/or PN on the screening day and were hemodynamically stable were recruited to this study. The observation period was described from the screening day (Day 1) for maximum of seven days.

\section{Exclusion criteria}

Patients admitted to the hospital for less than three days were excluded from the study because effects of nutrition on these patients were not considerable. Moreover, data of the patients were collected.

\section{Data collection and variables}

Nutritional statuses were assessed through measurement of anthropometric indices, clinical characteristics, laboratory values and medical histories by a registered dietitian using standard methods. Estimate weight was measured indirectly using Devine's method due to the lack of access to accurate weight measuring instruments (25). Mid upper arm circumference was used to estimate body mass index (BMI) (26). Biochemical indices such as blood glucose, albumin, magnesium, potassium, and BUN and creatinine levels were assessed during hospitalization. Dietary assessment was carried out to assess nutritional statuses, nutritional risks, types and volumes of the nutrition therapy and daily calorie and protein balances during the observation period. Patients' nutritional statuses were assessed based on the nutritional risks in critically ill (NUTRIC) score $(27,28)$. The NUTRIC score included six variables counting age, acute physiology, and chronic health evaluation (APACHE) II score, sequential organ failure assessment (SOFA) score, number of comorbidities, days from hospital to ICU admission and interleukin-6 (IL-6) (29). Gastrointestinal problems were assessed in these patients. Available data from the patients' records were collected for each day of stay in ICUs for seven days. The formula used by the patients during hospitalization included $1 \mathrm{kcal}$ of energy per milliliter of the formula; from which, $15 \%$ derived from proteins. Calorie balances were calculated as differences between daily caloric targets and daily calories provided by enteral and/or parenteral nutrition and other sources of calorie intakes. Daily protein balances were calculated as differences between clinician-derived daily protein targets and daily protein intakes (30). Daily calorie targets were derived by the clinician using standard formulas $(25 \mathrm{kcal} / \mathrm{kg}$ actual body weight on the screening day for patients in ICUs with no obesity) and daily protein targets using standard formulas (1.2 g/kg) (31). Cumulative calorie and protein balances were reported as sum of the mean daily balances for all days divided to seven days.

\section{Statistical analysis}

Quantitative variables were presented as mean \pm SD (standard deviation) and qualitative variables were reported as frequencies (\%).Primary outcomes were presented as continuous variables using mean differences between daily calorie targets and daily calorie intakes. Also, calorie intake of the patients were summarized as numbers and proportions in each of the following categories of $>90 \%$ of daily targets, and calorie deficits ( $\leq 90 \%$ of daily targets). In addition, nutritional characteristics of patients in each sex were categorized based on the following parameters: nutritional statuses, types of nutritional therapy and 7-days protein intake. The APACHE II score also was clarified based on severity of illness for each patients.

\section{Results}

The current study population included 35 men and 20 women with a median age of 30 and 52 years, respectively. Demographic, anthropometric measurements and biochemical values of the ICU inpatients are shown in Table 1. Of the patients, $7.3 \%$ included BMI of less than 18.5. The most common primary reason for admission to ICUs included trauma $(45.45 \%)$. The median points of APACHE-II and NUTRIC were 22 score (23 for males and 22 for females) and 3 score, respectively. The NUTRIC score in our study revealed that the risk of malnutrition was mild. The average albumin concentration included $3 \mathrm{~g} / \mathrm{dl}$ \pm 0.7 in ICU inpatients, demonstrating decreases in 
albumin levels compared to normal ranges $(3.5-5 \mathrm{~g} / \mathrm{dl})$ (32). Plasma magnesium and potassium levels were 0.65 and $4.06 \mathrm{mmol} / \mathrm{L}$ respectively, which showed hypomagnesia in patients (33). Of 55 patients admitted to ICUs, proportions of enteral, enteral/parenteral and total parenteral nutrition included 76.4, 18.2 and 5.5\%, respectively (Table 2). Analysis of the cumulative calorie balances from seven days revealed that the median 7-day

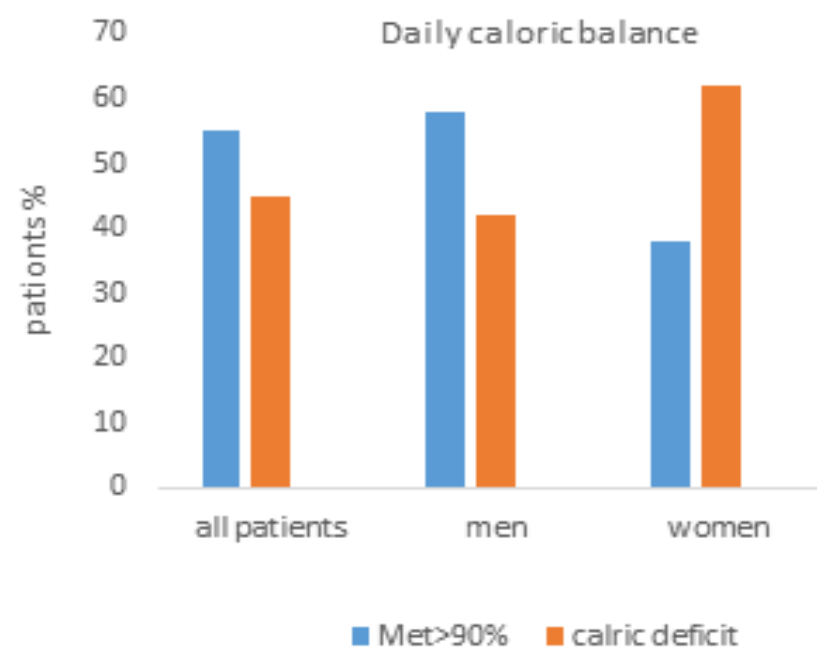

Figure 1. Daily caloric balance based. *Defined as divided the daily caloric intake based on sum of calories from enteral and/or parenteral nutrition and other sources of caloric intake on caloric target $=$ energy intake included $1691 \mathrm{kcal}$, while the median target energy included $1851 \mathrm{kcal}$. Results showed that calorie intake in men was less than $90 \%$ of the target calorie intake, while it was sufficient in women (Fig. 1). The median of 7-day protein intake was $69 \mathrm{~g}$, whereas the median target protein was $84 \mathrm{~g}$, showing that daily intake of protein was less than $1.2 \mathrm{~g} / \mathrm{kg}$ in patients (Fig. 2).

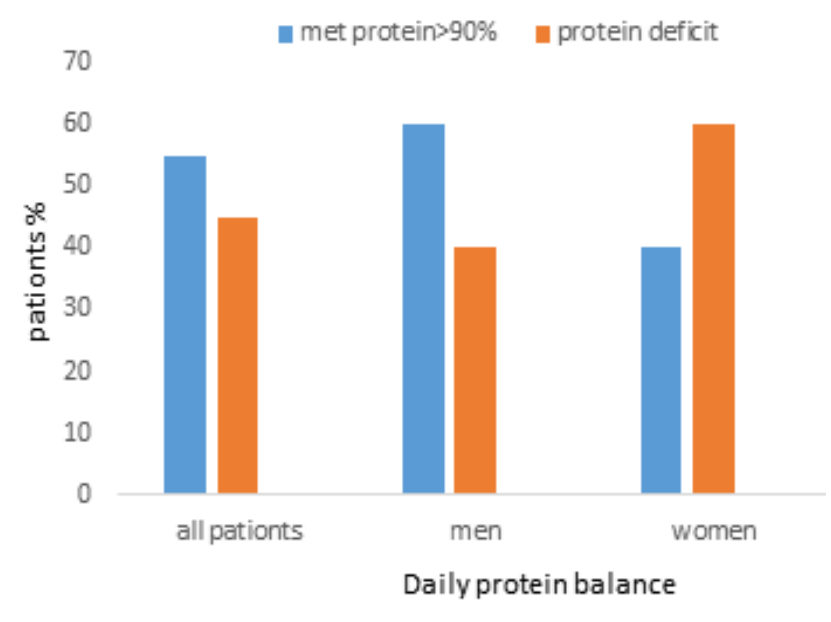

Figure 2.Daily protein balance based. *Defined as divided the daily protein intake based on sum of protein from enteral and/or parenteral nutrition and other sources of protein intake on protein target

Table 1. Baseline characteristics of the ICU patients

\begin{tabular}{|c|c|c|c|c|}
\hline & All patients $(\mathrm{n}=55)$ & $\operatorname{Male}(n=35)$ & Female $(n=20)$ \\
\hline \multirow{2}{*}{\multicolumn{2}{|c|}{$\begin{array}{l}\text { Age, median [IQR], y } \\
\text { Weight in bed, median [IQR], kg }\end{array}$}} & $37(18-80)$ & $30(18-80)$ & $52(31-77)$ \\
\hline & & $75(55-100)$ & $70(60-100)$ & $75(55-88)$ \\
\hline \multirow{3}{*}{$\begin{array}{l}\text { BMI in bed, median } \\
\text { [IQR], NO }(\%)\end{array}$} & $<18.5$ & $4(7.3)$ & $4(11.4)$ & 0 \\
\hline & $18.5-24.9$ & $21(38.2)$ & $14(40)$ & $7(35)$ \\
\hline & $\begin{array}{l}25-30 \\
>30\end{array}$ & $\begin{array}{c}24(43.6) \\
6(10.9)\end{array}$ & $\begin{array}{l}14(40) \\
3(8.6)\end{array}$ & $\begin{array}{c}10(50) \\
3(15)\end{array}$ \\
\hline \multirow{2}{*}{\multicolumn{2}{|c|}{$\begin{array}{l}\text { APACHE-II score, median [IQR] } \\
\text { NUTRIC score, median [IQR] }\end{array}$}} & $22(18-27)$ & $23(18-27)$ & $22(20-27)$ \\
\hline & & $3(2-5)$ & $3(2-5)$ & $3(2-5)$ \\
\hline \multirow[t]{3}{*}{ Admission type } & Medical, NO (\%) & $20(36.6)$ & $9(25.7)$ & $11(55)$ \\
\hline & Surgical, NO (\%) & $10(18.8)$ & 2(1) & $8(40)$ \\
\hline & Trauma, NO (\%) & $25(45.45)$ & $20(57.3)$ & $5(25)$ \\
\hline \multicolumn{2}{|c|}{ Weight during assessment, median [IQR], kg } & $73(50-96)$ & $73(50.7-96)$ & $77.6(55-91)$ \\
\hline \multicolumn{2}{|c|}{ Albumin $(\mathrm{g} / \mathrm{dl})$, mean $(\mathrm{SD})$} & $3(0.7)$ & $3(0.7)$ & $2.9(0.6)$ \\
\hline \multicolumn{2}{|c|}{ Blood glucose } & $145(62)$ & 122(19) & 186(86) \\
\hline \multicolumn{2}{|c|}{ Magnesium $(\mathrm{mmol} / \mathrm{L})$, mean [min-max] } & $0.65(0.22-1.41)$ & $0.7(0.25-1.54)$ & $0.6(0.2-1.31)$ \\
\hline \multicolumn{2}{|c|}{ Potassium $(\mathrm{mmol} / \mathrm{L})$, mean $[\min -\max ]$} & $4.06(3.0-5.5)$ & $3.87(3.0-5.5)$ & $4.4(3.4-5.5)$ \\
\hline \multicolumn{2}{|c|}{$\mathrm{BUN}(\mathrm{mg} / \mathrm{dl})$, mean (SD) } & $16.9(5)$ & $20(8)$ & $11(4)$ \\
\hline \multicolumn{2}{|c|}{ Creatinine $(\mathrm{mg} / \mathrm{dl})$, mean $(\mathrm{SD})$} & $1.1(0.9)$ & $1.1(0.8)$ & $1.1(0.6)$ \\
\hline
\end{tabular}


Table 2. Enteral and parenteral feedings in patients

\begin{tabular}{|c|c|c|c|c|}
\hline & & All patients $(\mathrm{n}=55)$ & $\operatorname{Male}(\mathrm{n}=35)$ & Female $(\mathrm{n}=20)$ \\
\hline \multirow[t]{2}{*}{ Feeding rout } & $\mathrm{EN}, \mathrm{NO}(\%)$ & $42(76.4)$ & $28(80)$ & $14(70)$ \\
\hline & $\begin{array}{l}\text { EN/PN, NO (\%) } \\
\text { TPN, NO (\%) }\end{array}$ & $\begin{array}{c}10(18.2) \\
3(5.5)\end{array}$ & $\begin{array}{l}5(14.3) \\
2(5.7)\end{array}$ & $\begin{array}{l}5(25) \\
1(5)\end{array}$ \\
\hline \multicolumn{2}{|c|}{ 7-days energy intake, Kcal, Median [IQR] } & 1691(750-2100) & $1600(750-2100)$ & $1830(1250-2100)$ \\
\hline \multicolumn{2}{|c|}{ Energy target, kcal, median [IQR] } & $1851(1500-2800)$ & $1850(1600-2800)$ & $1870(1500-2300)$ \\
\hline \multicolumn{2}{|c|}{ 7-days protein intake, g, Median [IQR] } & $69(38-90)$ & $68.5(38-90)$ & $66(38-88)$ \\
\hline \multicolumn{2}{|c|}{ Protein target, g, Median [IQR] } & $84(56-113)$ & $81(62-113)$ & $88(56-90)$ \\
\hline
\end{tabular}

Table 3. Occurrence of gastrointestinal problems in patients

\begin{tabular}{lccc}
\hline & All patients $(\mathrm{n}=55)$ & Male $(\mathrm{n}=35)$ & Female $(\mathrm{n}=20)$ \\
\hline Diarrhea, NO (\%) & $3(5.5)$ & $1(3)$ & $2(10)$ \\
Obstipation, NO (\%) & $7(12.7)$ & $6(17)$ & $1(5)$ \\
Gastric aspiration volume $>$ 250 mL, NO (\%) & $11(20)$ & $9(25.7)$ & $2(10)$ \\
Nausea and vomiting NO (\%) & $10(18.2)$ & $9(25.7)$ & $1(5)$ \\
\hline
\end{tabular}

Overall, $5.5 \%$ of the patients suffered from diarrhea, $12.7 \%$ from obstipation, $20 \%$ from gastric residual volumes of greater than $250 \mathrm{~mL}$ and $18.2 \%$ from nausea and vomiting (Table 3 ). Routes of feeding in patients with calorie deficits on the screening day are shown in Fig. 3; from which, the most common route was enteral feeding.

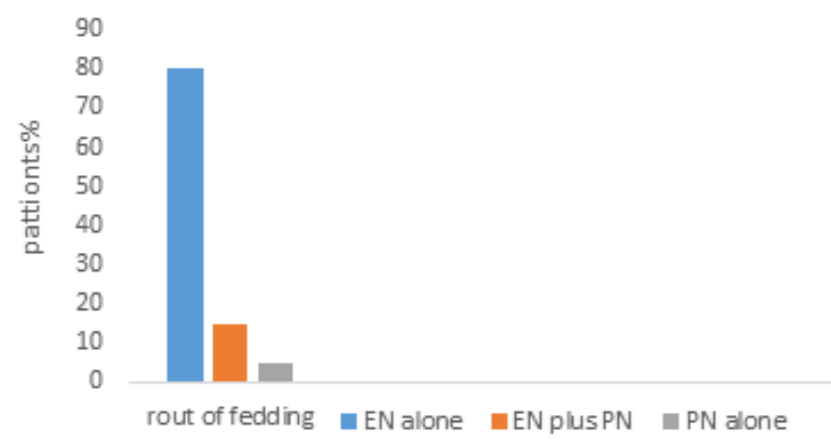

Figure 3.Proportion of patients with caloric deficit based on route of feeding in screening day 1. Abbreviations: EN: enteral nutrition, $\mathrm{PN}$ : parenteral nutrition

\section{Discussion}

In this cross-sectional study of nutritional statuses and gastrointestinal complications in ICU patients, critical malnutrition statuses were not observed in ICU inpatients based on the NUTRIC score. However, gastrointestinal problems were common in these cases. Moreover, decreases in serum albumin levels and hypo-magnesia were seen. Patients' protein and energy intakes were limited. In the present study, albumin levels were lower than normal ranges (32). Decreased levels of albumin, total protein and phosphorus were associated to malnutrition in the present study and patients with good nutritional statuses included higher albumin levels than those malnourished patients did $(25,34)$. It is noteworthy that each $10 \mathrm{~g} / \mathrm{L}$ decrease in serum albumin concentration significantly increased the odds of mortality by $137 \%$, morbidity by $89 \%$, prolonged
ICU and hospital stays by 28 and $71 \%$ respectively and increased resource utilization by $66 \%$ (35). Evidence indicated that two important potential confounding variables, malnutrition and inflammation, might explain the low albumin level effect (35). Interestingly, increased dietary protein intake and nutritional supplementation can improve low circulating albumin concentrations.

In further analysis, magnesium levels decreased in male and female ICU patients, compared to the normal range (33). Studies have shown that decreased circulating magnesium can be associated with higher mortality rates in critically ill patients (36). However, low levels of magnesium may result in decreased gastrointestinal (GI) absorption and increased renal loss, diarrhea, malabsorption and inadequate dietary protein and energy intakes (37). In critically ill patients with mild to moderate decreased plasma magnesium, administration of $1 \mathrm{~g}$ (8 $\mathrm{mEq}$ ) of intravenous $\mathrm{Mg}$ can increase serum $\mathrm{Mg}$ concentrations by $0.15 \mathrm{mEq} / \mathrm{L}$ within 18 to $30 \mathrm{~h}$ (38). Treatment of the associated electrolyte abnormalities and general management of the patients with focus on their nutritional therapy are necessary (39). Moreover, the current study has shown that daily calorie intake of the patients was lower than $90 \%$ of the energy targets. In published studies, the most important causes of malnutrition in ICU inpatients include calorie intake deficiency during the first days of admission and mechanical ventilation, which usually result in higher metabolic rates and further complications (40-42). Moreover, recent studies have shown that low calorie intakes are linked to nosocomial bloodstream infections and include negative effects on clinical outcomes of the ICU patients $(43,44)$.

In the last stage of analysis, consumed protein quantity failed to meet the target requirement $(1.2 \mathrm{~g} / \mathrm{kg})$. It is noteworthy that the formula used by the patients included $15 \%$ of proteins, which are not sufficient for the patients. 
The earlier studies have shown that lower protein intakes in ICU patients can lead to prolonged hospital stays, increased risks of malnutrition and impaired clinical outcomes $(25$, 30, 45). Moreover, studies have shown that this lack of adequate protein intake may be due to insufficient energy intake. Supplemental PN can improve energy and protein deliveries and potentially decrease risks of clinical side effects (30). Despite the low risks of malnutrition in patients this study, patients possibly develop malnutrition in long times. Therefore, necessary assessments must be carried out later since newly admitted patients receive insufficient energy and protein. In this study, more than half of the patients suffered from gastrointestinal problems. Obviously, gastrointestinal problems are common complications of the critical illnesses that can be characterized by constipation, abdominal distension, pain, nausea and vomiting and is associated with significant morbidities such as feeding intolerance, inadequate absorption of nutrients and medications and prolonged hospitalization (46). In ICUs, these gastrointestinal problems are linked to gastrointestinal motility, altered by drugs, immobility, surgery, enteral feeding, head and spinal injuries, inflammation and sepsis (46). Therefore, understanding causes of gastrointestinal intolerance and resolving them can significantly affect the clinical status of ICU patients.

\section{Strengths of the study}

Strengths of the study include assessment of nutritional statuses of ICU patients that can be used in future interventions and use of standard instruments to assess biochemical values. However, it is noteworthy that the current study included several limitations as follows: 1) cross-sectional study and follow-up impossibility, 2) lack of direct calorimeter devices and inability of accurate calculation of the necessary calories, 3) lack of body composition analyzers and use of arm circumference to estimate current weights, and 4) lack of other biochemical and clinical tests other than hospital routine tests.

\section{Conclusions}

In conclusion, these results have suggested that clinical and biochemical factors such as energy and protein requirements, gastrointestinal complications and magnesium levels are abnormal in ICU patients, especially in women. However, risk assessments of the malnutrition have shown no critical results using nutritional screening tools. Therefore, these cases can be used as warning predictors of the malnutrition in long terms and must be reassessed in the future. In addition, well-designed clinical trials are necessary to clarify all aspects of the nutritional supplementation.

\section{Financial disclosure}

The authors declare no financial interest.

\section{Funding/Support}

This work was financially supported by the Food Security Research Center, Isfahan University of Medical Sciences, Isfahan, Iran.

\section{References}

1. White JV, Guenter P, Jensen G, Malone A, Schofield M. Consensus statement: Academy of Nutrition and Dietetics and American Society for Parenteral and Enteral Nutrition: characteristics recommended for the identification and documentation of adult malnutrition (undernutrition). JPEN Journal of parenteral and enteral nutrition. 2012;36(3):275-83.

2. Barker, L.A., B.S. Gout, and T.C. Crowe, Hospital malnutrition: prevalence, identification and impact on patients and the healthcare system. International journal of environmental research and public health, 2011. 8(2): p. 514527.

3. Soeters, P.B., et al., A rational approach to nutritional assessment. Clin Nutr, 2008. 27(5): p. 706-16.

4. Banks M, Ash S, Bauer J, Gaskill D. Prevalence of malnutrition in adults in Queensland public hospitals and residential aged care facilities. Nutrition \& Dietetics. 2007;64(3):172-8.

5. Moghadam $\mathrm{AD}$, et al. Evaluation of nutritional quality and microbial contamination of enteral feeding solutions in hospitalized patients referred to neurosurgical ICU of Poursina Hospital in Rasht. Pejouhandeh. 2010. 15(5 (77)): p.Pe213Pe219

6. Correia MI, Waitzberg DL. The impact of malnutrition on morbidity, mortality, length of hospital stay and costs evaluated through a multivariate model analysis. Clinical nutrition (Edinburgh, Scotland). 2003;22(3):235-9.

7. Stratton RJ, King CL, Stroud MA, Jackson AA, Elia M. 'Malnutrition Universal Screening Tool' predicts mortality and length of hospital stay in acutely ill elderly. The British journal of nutrition. 2006;95(2):325-30.

8. Norman K, Pichard C, Lochs H, Pirlich M. Prognostic impact of disease-related malnutrition. Clinical nutrition (Edinburgh, Scotland). 2008;27(1):5-15.

9. Sorensen J, Kondrup J, Prokopowicz J, Schiesser M, Krahenbuhl L, Meier R, et al. EuroOOPS: an international, multicentre study to implement nutritional risk screening and evaluate clinical outcome. Clinical nutrition (Edinburgh, Scotland). 2008;27(3):340-9.

10. Lim SL, Ong KC, Chan YH, Loke WC, Ferguson M, Daniels L. Malnutrition and its impact on cost of hospitalization, length of stay, readmission and 3-year mortality. Clinical nutrition (Edinburgh, Scotland). 2012;31(3):345-50.

11. Alvarez-Hernandez J, Planas Vila M, Leon-Sanz M, Garcia de Lorenzo A, Celaya-Perez S, Garcia-Lorda P, et al. Prevalence and costs of malnutrition in hospitalized patients; the PREDyCES Study. Nutricion hospitalaria. 2012;27(4):1049-59.

12. Brito PA, de Vasconcelos Generoso S, Correia MI. Prevalence of pressure ulcers in hospitals in Brazil and association with nutritional status--a multicenter, cross-sectional study. Nutrition (Burbank, Los Angeles County, Calif). 2013;29(4):646-9.

13. Waitzberg DL, Caiaffa WT, Correia MI. Hospital malnutrition: the Brazilian national survey (IBRANUTRI): a study of 4000 patients. Nutrition (Burbank, Los Angeles County, Calif). 2001;17(7-8):573-80. 
14. Leandro-Merhi VA, de Aquino JL, Sales Chagas JF. Nutrition status and risk factors associated with length of hospital stay for surgical patients. JPEN Journal of parenteral and enteral nutrition. 2011;35(2):241-8.

15. McClave SA, Taylor BE, Martindale RG, Warren MM, Johnson DR, Braunschweig C, et al. Guidelines for the Provision and Assessment of Nutrition Support Therapy in the Adult Critically Ill Patient: Society of Critical Care Medicine (SCCM) and American Society for Parenteral and Enteral Nutrition (A.S.P.E.N.). JPEN Journal of parenteral and enteral nutrition. 2016;40(2):159-211.

16. Singer P, Berger MM, Van den Berghe G, Biolo G, Calder P, Forbes A, et al. ESPEN Guidelines on Parenteral Nutrition: intensive care. Clinical nutrition (Edinburgh, Scotland). 2009;28(4):387-400.

17. Higgins PA, Daly BJ, Lipson AR, Guo S-E. Assessing nutritional status in chronically critically ill adult patients. Am J Crit Care. 2006;15(2):166-77.

18. Moreno JP, de la Mata Navazo S, Arteta EL-H, Hernani MT, Martínez FG, Sánchez MIG, et al. Influence of nutritional status on clinical outcomes in hospitalised children. Anales de Pediatría (English Edition). 2019;91(5):328-35.

19. Ordoñez AM, Schieferdecker MEM, Cestonaro T, Neto JC, Campos ACL. Nutritional status influences the length of stay and clinical outcomes in hospitalized patients in internal medicine ward. Nutricion hospitalaria. 2013;28(4):1313-20.

20. Sauer A. Hospital malnutrition: Assessment and intervention methods. Online). www. abbottNutritionHealthInstitute. org yang diakses pada tanggal; 2011.

21. Saleh WA, Khalil PB, Ouaijan K, Abillama F, Akiki S, Ahmad $\mathrm{N}$, et al. Evaluation of nutrition support practices: Results from a nationwide survey. Clinical Nutrition. 2018;37(6):1976-9.

22. De Luis D, Izaola O, Velicia M, Antolín GS, Pajares FG, Terroba M, et al. Impact of dietary intake and nutritional status on outcomes after liver transplantation. Revista Espanola de Enfermedades Digestivas. 2006;98(1):6.

23. Samadi M, Zeinali F, Habibi N, Ghotbodin-Mohammadi S. Intake of dietary supplements and malnutrition in patients in intensive care unit. International journal of preventive medicine. 2016;7.

24. Mahan LK, Escott-Stump S, Raymond JL, Krause MV. Krause's food \& the nutrition care process: Elsevier Health Sciences; 2012.

25. Azadbakht L, Abbasi S, Hajishafiee M, Feizi A, Mohajeri G, Nemani F, et al. Determinants of malnutrition in critically ill patients admitting to ICU in Iran. Progress in Nutrition. 2019;21(1-S):220-6.

26. Lamb CA, Parr J, Lamb EI, Warren MD. Adult malnutrition screening, prevalence and management in a United Kingdom hospital: cross-sectional study. British journal of nutrition. 2009;102(4):571-5.

27. Rahman A, Hasan RM, Agarwala R, Martin C, Day AG, Heyland DK. Identifying critically-ill patients who will benefit most from nutritional therapy: further validation of the "modified NUTRIC" nutritional risk assessment tool. Clinical nutrition. 2016;35(1):158-62.

28. Cederholm T, Bosaeus I, Barazzoni R, Bauer J, Van Gossum A, Klek S, et al. Diagnostic criteria for malnutrition-an ESPEN consensus statement. Clinical nutrition. 2015;34(3):335-40.

29. Jung YT, Park JY, Jeon J, Kim MJ, Lee SH, Lee JG. Association of Inadequate Caloric Supplementation with 30-
Day Mortality in Critically Ill Postoperative Patients with High Modified NUTRIC Score. Nutrients. 2018;10(11):1589.

30. Vallejo KP, Martínez CM, Adames AAM, Fuchs-Tarlovsky V, Nogales GCC, Paz RER, et al. Current clinical nutrition practices in critically ill patients in Latin America: a multinational observational study. Critical care. 2017;21(1):227.

31. Singer P, Blaser AR, Berger MM, Alhazzani W, Calder PC, Casaer MP, et al. ESPEN guideline on clinical nutrition in the intensive care unit. Clinical Nutrition. 2019;38(1):48-79.

32. Bae H-J, Lee H-J, Han D-S, Suh Y-S, Lee Y-H, Lee H-S, et al. Prealbumin levels as a useful marker for predicting infectious complications after gastric surgery. Journal of Gastrointestinal Surgery. 2011;15(12):2136-44.

33. Efstratiadis G, Sarigianni M, Gougourelas I. Hypomagnesemia and cardiovascular system. Hippokratia. 2006;10(4):147.

34. Robinson MK, Trujillo EB, Mogensen KM, Rounds J, McManus K, Jacobs DO. Improving nutritional screening of hospitalized patients: the role of prealbumin. Journal of Parenteral and Enteral Nutrition. 2003;27(6):389-95.

35. Vincent J-L, Dubois M-J, Navickis RJ, Wilkes MM. Hypoalbuminemia in acute illness: is there a rationale for intervention? A meta-analysis of cohort studies and controlled trials. Ann Surg. 2003;237(3):319-34.

36. Limaye C, Londhey V, Nadkart M, Borges $N$. Hypomagnesemia in critically ill medical patients. J Assoc Physicians India. 2011;59(1):19-22.

37. Mouw DR, Latessa RA, Sullo EJ. What are the causes of hypomagnesemia? Clinical Inquiries, 2005 (MU). 2005.

38. Hansen B-A, Bruserud Ø. Hypomagnesemia in critically ill patients. Journal of intensive care. 2018;6(1):21.

39. Martin KJ, González EA, Slatopolsky E. Clinical consequences and management of hypomagnesemia. Journal of the American Society of Nephrology. 2009;20(11):2291-5.

40. Edington J, Boorman J, Durrant E, Perkins A, Giffin C, James $\mathrm{R}$, et al. Prevalence of malnutrition on admission to four hospitals in England. Clinical Nutrition. 2000;19(3):191-5.

41. Braunschweig C, Gomez S, Sheean PM. Impact of declines in nutritional status on outcomes in adult patients hospitalized for more than 7 days. Journal of the American Dietetic Association. 2000;100(11):1316-22.

42. Dvir D, Cohen J, Singer P. Computerized energy balance and complications in critically ill patients: an observational study. Clinical Nutrition. 2006;25(1):37-44.

43. Rubinson L, Diette GB, Song X, Brower RG, Krishnan JA. Low caloric intake is associated with nosocomial bloodstream infections in patients in the medical intensive care unit. Critical care medicine. 2004;32(2):350-7.

44. Villet S, Chiolero RL, Bollmann MD, Revelly J-P, Cayeux M$\mathrm{C}$, Delarue J, et al. Negative impact of hypocaloric feeding and energy balance on clinical outcome in ICU patients. Clinical Nutrition. 2005;24(4):502-9.

45. Weijs PJ, Wischmeyer PE. Optimizing energy and protein balance in the ICU. Current Opinion in Clinical Nutrition \& Metabolic Care. 2013;16(2):194-201.

46. Nguyen T, Frenette A-J, Johanson C, MacLean RD, Patel R, Simpson A, et al. Impaired gastrointestinal transit and its associated morbidity in the intensive care unit. Journal of Critical Care. 2013;28(4):537.e11-.e17. 